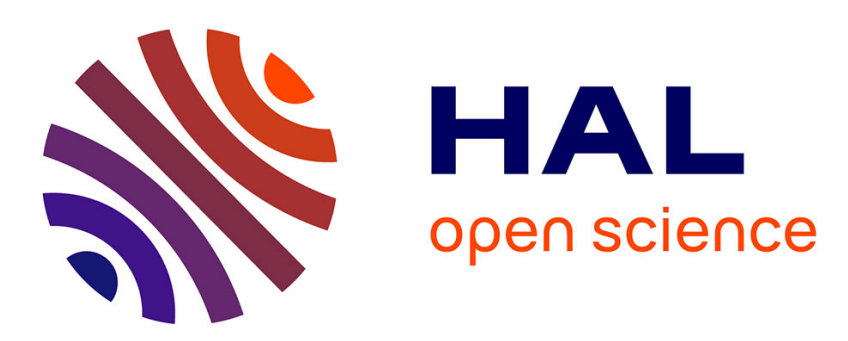

\title{
Mechanically Robust Antibacterial Nanopapers Through Mixed Dimensional Assembly for Anionic Dye Removal
} P. Nizam, Vishnu Arumughan, Aloshy Baby, M. Sunil, Daniel Pasquini, Ange Nzihou, Sabu Thomas, Deepu Gopakumar

\section{- To cite this version:}

P. Nizam, Vishnu Arumughan, Aloshy Baby, M. Sunil, Daniel Pasquini, et al.. Mechanically Robust Antibacterial Nanopapers Through Mixed Dimensional Assembly for Anionic Dye Removal. Journal of Polymers and the Environment, 2020, 28, pp.1279-1291. 10.1007/s10924-020-01681-3 . hal-02496909

\section{HAL Id: hal-02496909 https://imt-mines-albi.hal.science/hal-02496909}

Submitted on 17 Jul 2020

HAL is a multi-disciplinary open access archive for the deposit and dissemination of scientific research documents, whether they are published or not. The documents may come from teaching and research institutions in France or abroad, or from public or private research centers.
L'archive ouverte pluridisciplinaire HAL, est destinée au dépôt et à la diffusion de documents scientifiques de niveau recherche, publiés ou non, émanant des établissements d'enseignement et de recherche français ou étrangers, des laboratoires publics ou privés. 


\title{
Mechanically Robust Antibacterial Nanopapers Through Mixed Dimensional Assembly for Anionic Dye Removal
}

\author{
P. A. Nizam ${ }^{1} \cdot$ Vishnu Arumughan ${ }^{1,2} \cdot$ Aloshy Baby $^{1} \cdot$ M. A. Sunil ${ }^{3} \cdot$ Daniel Pasquini ${ }^{4} \cdot$ Ange Nzihou $^{5} \cdot$ Sabu Thomas $^{1}$. \\ Deepu A. Gopakumar ${ }^{5}$ (i)
}

\begin{abstract}
There is a piqued interest in development of biobased sorbents for water treatment. Here in we reported, the fabrication of mechanically strong nanopapers by mixed dimensional assembly of 1D Cellulose nanofibers and 2D amino functionalized graphene oxide for water treatment. The fabricated amino functionalized GO/ cellulose nanofiber (AMGO-CNF) nanopaper showed superior antibacterial resistance towards Escherichia coli MTCC 1610 and Klebsiella due to the enhanced surface roughness which was confirmed from SEM and AFM studies. The amino group present in the AMGO enhanced the adsorption efficiency of the nanopaper towards methyl orange dye. The fabricated nanopaper showed an adsorption of $11.05 \mathrm{mg} / \mathrm{gm}$ $30 \mathrm{mg} / \mathrm{L}$ concentration at $\mathrm{pH}$ 2. Maximum adsorption was observed at $\mathrm{pH} 2$ which was due to protonation of amine group. Moreover, the fabricated membrane showed excellent hydrolytic stability which can be corroborated to the surface roughness and reduced hydrophilicity. The investigation into the surface chemistries of cellulose nanofibers beyond the adoption of toxic solvents can enhance the economic usefulness of the process and yield a new eco-friendly adsorbent material that is agreeable to adsorbing various toxic pollutants.
\end{abstract}

Deepu A. Gopakumar

deepu1789@gmail.com

1 School of Chemical sciences, Mahatma Gandhi University,

Kottayam, Kerala 686560, India

2 Department of Chemistry and Chemical engineering, Chalmers University of technology, Gothenburg, Sweden

3 School of Bio sciences, Mahatma Gandhi University, Kottayam, Kerala 686560, India

4 Chemistry Institute, Federal University of Uberlandia-UFU, Campus Santa Monica- Bloco1D-CP 593, Uberlandia, Brazil

5 Université de Toulouse, IMT Mines Albi, RAPSODEE CNRS UMR-5302, Campus Jarlard, Albi Cedex 09 81013, France 


\section{Graphic Abstract}

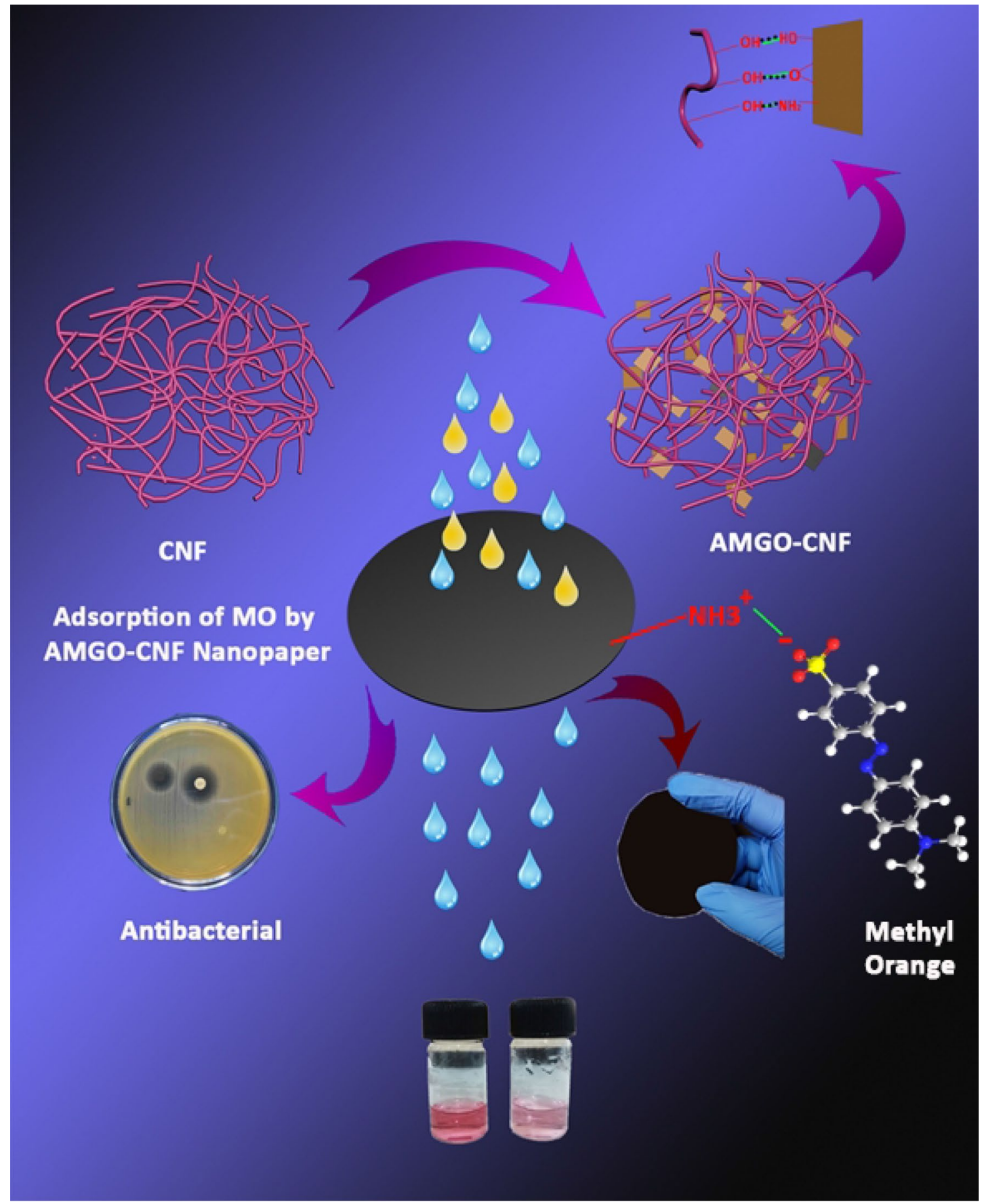

Keywords Cellulose nanofibers · Graphene oxide · Water purification

\section{Introduction}

The rising industrialization has polluted the fresh water resources to such an extent that the survival has become a threat [1]. With the development of newer varieties of modern industries, the pollutants like toxic textile dyes, bacteria, suspended minute particles entering into fresh water resources are bound to go on enhancing [2]. Therefore the 
removal of dyes, bacteria and suspended minute particles has become an integral discussion of our technological society. Another major effect due to industrial effluents is the rise in pathogenic bacteria [3]. These bacteria can be distinguished into two categories, gram negative and gram positive, gram negative being reported as most hospital-acquired infectious species [4]. Escherichia coli and Klebsiella pneumoniae are two gram-negative bacteria and their presence in water is ultimately pointing towards water pollution [5]. E. coli is considered as an indicator of the bacteriological quality of water [6].

Biological processes, chemical processes, operation of electromagnetic radiation etc. are the common removal techniques [7]. From these techniques ultrafiltration (UF), microfiltration (MF), and nanofiltration (NF) with pressure driven techniques have achieved substantial attention owing to their remarkably high performance and cost effective in nature [8]. Now a days, numerous scientists across the world have been extensively using electrospinning technology to fabricate water filtration membranes with high strength and uniform pore size [9]. However, the electrospinning technique is too costly to commercialize at industrial level. In this context an eco-friendly, cost effective and efficient method is very crucial since the commercially available synthetic polymer membranes eventually end up as non-degradable waste.

Biopolymers, due to its excellent biodegradability and physiochemical properties has gained immense attention and presumably replacing all the other commercial materials same time offering best prospects [10]. Among the numerous biopolymers, isolated cellulose stands foremost due to its excellent chemical, physical and biodegradable properties [11]. Cellulose are bio polymers mostly isolated from wood [12,13]. Other sources include algae, bacteria and tunicate, the only animal resource [14]. The extracted cellulose nanofibers have inherent properties such as good mechanical properties and high specific surface area [15]. One dimensional (1 D) cellulose nanofibers (CNFs) are one of the promising adsorbent materials for water purification due to their low cost, abundant hydroxyl groups, natural abundance, and ecofriendly nature [16]. Additionally, the CNFs have the immense amount of surface hydroxyl $(\mathrm{OH})$ groups, which facilitates diverse surface modifications via incorporation of chemical moieties that may lead to the adsorption toward the various pollutants in water [17]. On the other hand, Graphene oxide (GO) is another class of cost effective two dimensional (2D)nanomaterial emerged in recent years which could be effectively used for water purification [18]. The highly reactive nature of GO due to hydroxy, epoxy and carboxylic groups enables various surface chemistries which can be explored for the removal of various pollutants from water [19].

Until, there has been no studies reported on amino functionalized GO/cellulose nanofiber (AMGO-CNF) nanopaper for water purification. The study carried out by Zhu et al. reported a cellulose-GO hybrid membrane for water purification [20]. The demonstrated membrane had a synergistic property of adsorption of $\mathrm{Cu}$ (II), flexibility, hydrolytic stability and mechanical robustness. Another work reported by Fryczkowska et al. investigated the physico-chemical and transport properties of GO/Cellulose membranes [21]. Meng et al. shredded light on toughening mechanism of cellulose nanopaper by developing a multiscale crack-bridging model [22]. Meng et al also developed a theoretical model to understand the effect of nano-fiber alignment in fracture toughness of CNF nanopaper [23]. A review by Meng et al. discusses the effect of orientation, polymerization degree, density, porosity and humidity of nanopaper, lignin on the mechanical properties of CNF nanopaper [24]. In this context, we are intended to fabricate a novel functional nanopaper by mixed dimensional assembly of 1D Cellulose nanofibers (CNFs) and 2D Amino functionalized graphene oxide (AMGO) via simple vacuum filtration process for removing toxic textile dyes. We have functionalized the GO to introduce amine groups on the surface of nanopaper in order to enhance the adsorption towards anionic dyes as well as introduce excellent antibacterial property.

\section{Experimental Section}

\section{Materials}

Cellulose nanofibers (CNFs) were procured from SUZANO, Brazil with diameter in the nano range of $20-30 \mathrm{~nm}$. Graphene Oxide was synthesised in lab using Improved Hummers Method. Methyl Orange, sulphuric acid, phosphoric acid, $\mathrm{KMnO}_{4}$ were purchased from Sigma Aldrich.

\section{Synthesis of Graphene Oxide}

Graphene oxide (GO) was prepared by modified hummers method using $\mathrm{KMnO}_{4}$ as oxidising agent. 3:1 ratio of sulphuric acid and phosphoric acid were taken, onto which 0.09 gm of graphite powder were added under constant stirring. Oxidising agent $\mathrm{KMnO}_{4} 0.9$ gm was added when uniform dispersion was achieved, and the mixture was stirred for $7 \mathrm{~h}$. $15 \mathrm{ml}$ of hydrogen peroxide was added to react any remaining reactant. The resultant GO was washed with ethanol and water till the $\mathrm{pH}$ was adjusted to 7 [25].

\section{Amino Functionalization of Graphene oxide}

A hydrothermal method was employed for functionalization of Graphene Oxide [26]. $0.5 \mathrm{gm}$ of hydrous ferric chloride, $3 \mathrm{gm}$ of Sodium acetate and functionalising agent Diethylene Triamine were stirred vigorously for $1 \mathrm{~h}$ on a magnetic 
stirrer. The mixture was transferred to a stainless-steel enclosed Teflon autoclave and reacted at $200{ }^{\circ} \mathrm{C}$ for $6 \mathrm{~h}$. After cooling to room temperature, the product was washed with ethanol and deionized water for several times to remove any unreacted product. The final product, amine functionalised Graphene oxide AMGO was dried at $60^{\circ} \mathrm{C}$ for $24 \mathrm{~h}$.

\section{Fourier Transform Infrared Spectroscopy, Raman Spectroscopy and XRD Analysis}

The prepared graphene oxide and amine functionalised graphene oxide were characterised using Fourier Transform infrared spectroscopy from 4000 to $400 \mathrm{~cm}^{-1}$ wavelengths to confirm the materials. FT-IR on fabricated nanopapers were also carried out. Raman imaging of graphene oxide and amine functionalised graphene oxide were recorded from 200 to $2000 \mathrm{~cm}^{-1}$ using Spectroscopy Model Alpha 300R. The X-ray diffraction (XRD) diffraction patterns were obtained at diffraction angles between $5^{\circ}$ and $40^{\circ}$ with a scanning rate of $0.4 \% \mathrm{~min}$ at room temperature using Rigaku MiniFlex600 XRD analyser.

\section{Scanning Electron Microscopy and Atomic Force Microscopy}

The morphology of cellulose and AMGO-CNF nanopapers were examined using Scanning Electron Microscopy JEOL-Model JSM 6390. Samples were gold sputtered in an argon atmosphere. Analysis was carried out at $20 \mathrm{KV}$ with $20 \mu \mathrm{m}$ magnification. Surface roughness of nanopapers was analysed using Atomic Force Microscopy (A.P.E Research, Italy). The nanopapers were cut into $0.25 \mathrm{~cm}^{2}$ size area and attached to plate of area $50 \mathrm{~cm}^{2}$ using a double-sided tape. The nanopapers were characterized by a size of $2.5 \times 2.5 \mu \mathrm{m}$ with an aid of tapping tool.

\section{UV-Visible Spectrophotometer}

Anionic dye adsorption was evaluated using Thermo Scientific Evolution 201 UV-Vis Spectrophotometer by absorbance technique. Samples were tested at different time intervals by pouring the solution to UV cuvette. Calibration of the sample for absorbance was done using water as reference. The absorbance was measured at $507 \mathrm{~nm}$. Concentration of starting and final solutions were determined by UV-Vis spectroscopy.

\section{Evaluation of Porosity of CNF and CNF-AMGO Nanopaper}

The porosity of CNF and CNF-AMGO nanopaper were determined using gravimetric method using following Eq. (1),
Porosity $\varepsilon=\mathrm{W}_{\mathrm{w}}-\mathrm{W}_{\mathrm{d}} / \mathrm{A} \times \mathrm{L} \times \mathrm{p}$

where $\mathrm{W}_{\mathrm{w}}$ and $\mathrm{W}_{\mathrm{d}}$ is wet and dry weight of nanopaper respectively, $\mathrm{A}$ is the nanopaper effective area, $\mathrm{L}$ the thickness of the membrane and $p$ is the density of water.

The average nanopaper pore radius was calculated by Guerout Elford-Ferry Equation given in Eq. (2)

$\sqrt{ }(2.9-1.75 \varepsilon) 8 \mathrm{nLQ} / \varepsilon \times \mathrm{A} \times \Delta \mathrm{P}$

where $\mathrm{n}$ is the water viscosity $\left[\left(8.9 \times 10^{-4} \mathrm{~Pa} \mathrm{~s}\right) \mathrm{Q}\right.$ is water flux $\left(\mathrm{m}^{3} / \mathrm{s}^{-1}\right)$ and $\Delta \mathrm{P}$ operational pressure which is $1.5 \mathrm{bar}$ pressure. The flux was calculated using dead end filtration technique using Sterlitech model HP4750 stirred cell shown in Fig. 1.

\section{Evaluation of Anionic Dye Adsorption by AMGO-CNF Nanopaper}

Methyl orange (MO) was used as a model compound for the anionic dye adsorption study. Various concentration of dyes was prepared for this study $5,10,20$ and $30 \mathrm{mg} / \mathrm{l}$ respectively. Initially, $0.5 \mathrm{gm}$ of AMGO-CNF nanopaper was weighed and immersed in $50 \mathrm{ml}$ of dye solution, placed on a shaking bed at ambient temperature. At different time intervals the samples were collected to evaluate the concentration of dye. The study was carried out at varying $\mathrm{pH}$ of 2 , 5, 7 and 10. The adsorption efficiency of the AMGO-CNF nanopaper was assessed from change in concentration of

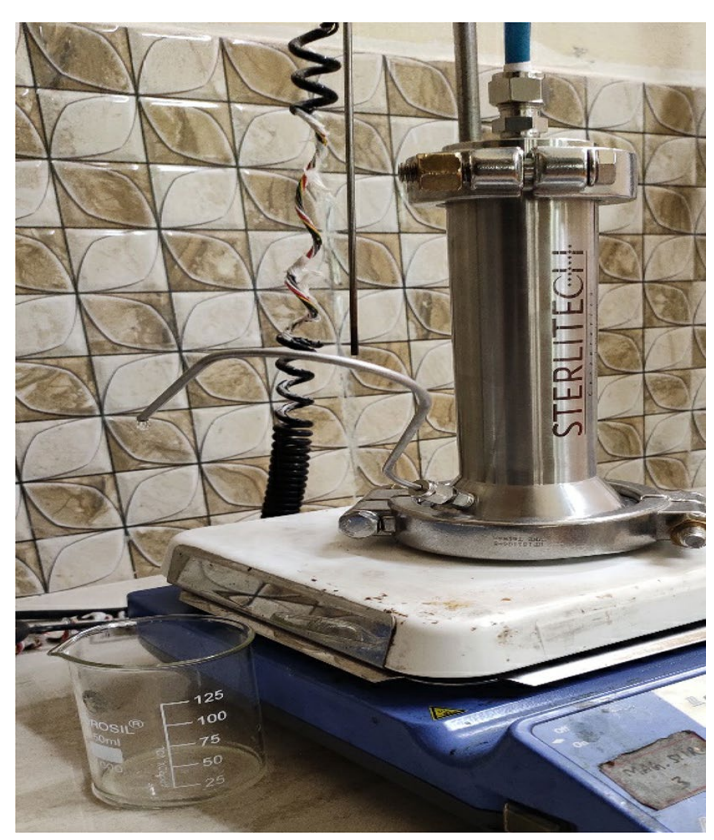

Fig. 1 Dead end filtration technique using Sterlitech model HP4750 stirred cell 
MO solution before and after the test using UV spectroscopy at $507 \mathrm{~nm}$. Absorbance of the nanopaper was calculated using beer lambert's equation and adsorption capacity were evaluated by following equation [27].

Adsorption Capacity $(\mathrm{mg} / \mathrm{g})=\left(\mathrm{C}_{0}-\mathrm{C}\right) \mathrm{L} / \mathrm{G}$

where $\mathrm{C}_{0}$ is initial concentration, $\mathrm{C}$ is the concentration at time $\mathrm{T}, \mathrm{L}$ is volume of solution taken for test and $\mathrm{G}$ is weight of nanopaper $(\mathrm{g})$.

\section{Antibacterial Action of the Fabricated AMGO-CNF Nanopaper}

Antibacterial studies were carried out on cellulose and modified nanopapers via Kirby Bauer Disc diffusion method[28]. A $4 \mathrm{~mm}$ thick Mueller-Hinton Agar plates were prepared after incubation for $20 \mathrm{~min}$ at $121^{\circ} \mathrm{C}$. Test organisms such as E. Coli MTCC 1610 and Klebsiella, (Gram Negative) were used in this study. Inoculum preparation was done using a $\log$ phase method where four to five well isolated colonies of bacteria were transferred from an agar plate using a loop to a Muller-Hinton broth. This was then incubated at $35^{\circ} \mathrm{C}$ until a turbidity of $0.5 \mathrm{McF}$ arland standard was achieved (approx. 1 to $2 \times 10^{8} \mathrm{CFU} \mathrm{ml}{ }^{-1}$ ). $\mathrm{BaSO}_{4}$ turbid solution was used as a standard for inoculum density. This solution was equivalent to $0.5 \mathrm{McF}$ arland standard. The bacterial suspension was uniformly inoculated to a prepared MHA plate using a sterilise swap. The cellulose and AMGO-CNF nanopaper were placed on to this agar plate using a sterilise forceps. These discs were gently pressed to get complete contact with the agar surface. Streptomycin ( $25 \mu \mathrm{g}$ per disc) were used as positive control for all the bacteria. These plates were incubated at $37{ }^{\circ} \mathrm{C}$ for $20 \mathrm{~h}$. After $20 \mathrm{~h}$ zone of inhibition was measured.

\section{Contact Angle of Fabricated AMGO-CNF Nanopaper}

In order to determine the extent of hydrophilicity, the contact angle test was carried out using SEO-Phoenix 300 model. The source light was focused on instrument on hand camera and deionized water was used as probe liquid. Three contact angles were measured at different places of the sample and the average value is reported.

\section{Mechanical Property of AMGO-CNF Nanopaper}

Mechanical test was conducted using UTM model Tinius Olsen H50KT. Samples were prepared with a thickness of 5 $\mathrm{mm}$ and the test was conducted with a deformation of $5 \mathrm{~mm}$ $\min ^{-1}$ using $100 \mathrm{~N}$ load cell.

\section{Result and Discussion}

\section{Characterisation of GO and AMGO Using FT-IR and Raman Spectroscopy}

In order to confirm the amine functionalization on GO, FTIR and Raman spectroscopy of both graphene oxide (GO) and amino functionalized graphene oxide (AMGO) were studied [26]. Figure 2a shows the FTIR and Raman spectra of GO and AMGO. From the Fig. 2, GO shows peak at $1041 \mathrm{~cm}^{-1}$ (C-O epoxy stretching), $1220 \mathrm{~cm}^{-1}$ (C-OH stretching),1625
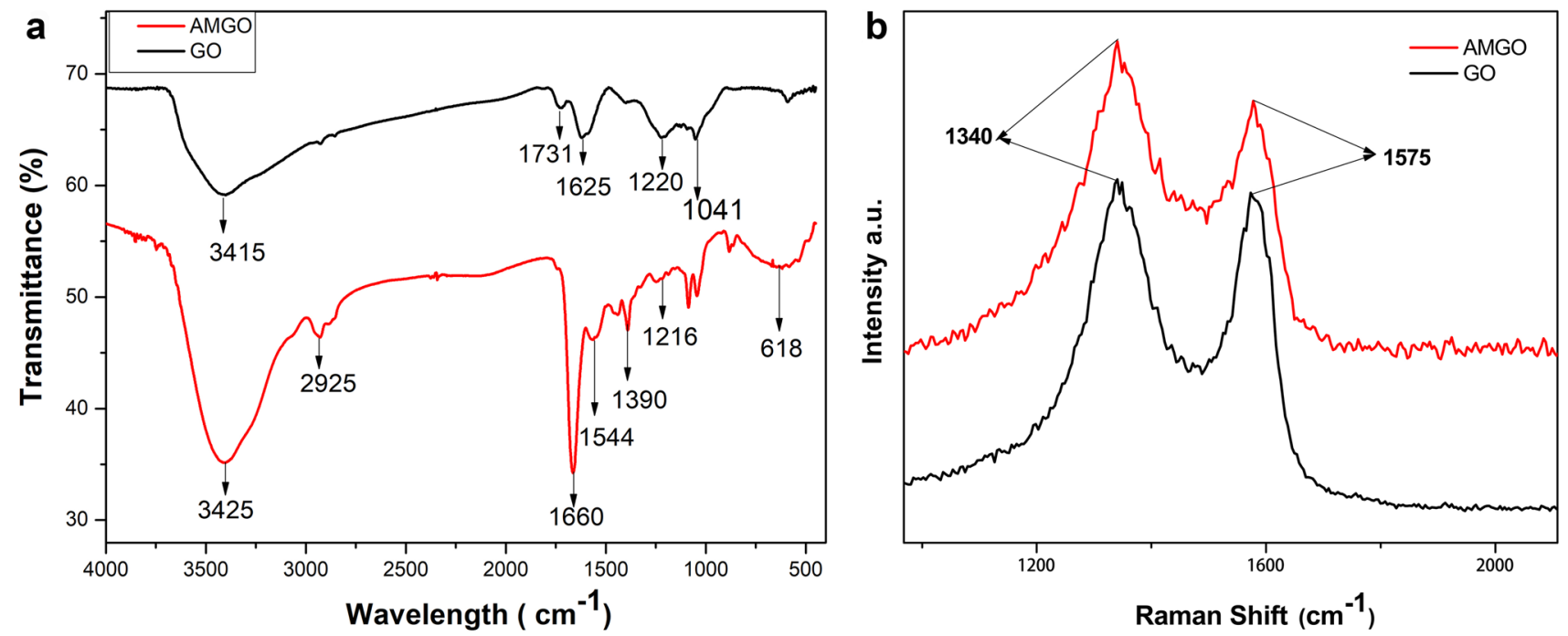

Fig. 2 a FTIR Spectrum of GO and AMGO and $\mathbf{b}$ Raman spectra of GO and AMGO 
$\mathrm{cm}^{-1}$ ( $\mathrm{C}=\mathrm{C}$ stretching $), 1731 \mathrm{~cm}^{-1}(\mathrm{C}=\mathrm{O}$ stretching $)$ and $3415 \mathrm{~cm}^{-1}$ (-OH stretching). The presence of these groups confirmed the formation of GO. In the case of AMGO, a new peak has emerged at $1390 \mathrm{~cm}^{-1}$ indicating the $\mathrm{C}-\mathrm{N}$ stretching vibration. The band at $1544 \mathrm{~cm}^{-1}$ was attributed to the formation of stretching and bending vibration of $\mathrm{N}-\mathrm{H}$ Bond. Medium peaks or bands at free region can be described as asymmetric $\mathrm{C}-\mathrm{N}$ vibration coupled with $\mathrm{NH}_{2}$ or $\mathrm{N}-\mathrm{H}$ modes. The disappearance of peak at $1731 \mathrm{~cm}^{-1}(\mathrm{C}=\mathrm{O}$ stretch of $\mathrm{COOH}$ ) of FTIR spectrum in AMGO confirms the successful amino functionalization of GO[29]. Raman spectroscopy showed the presence of defects on graphite layer. Figure $2 b$ shows the Raman spectra of GO and AMGO. Figure $2 \mathrm{~b}$ shows two peaks at $1340 \mathrm{~cm}^{-1}$ and $1575 \mathrm{~cm}^{-1}$ for both GO and AMGO which can be attributed to D band and $\mathrm{G}$ band respectively. D band represents the defect band $\left(\mathrm{SP}^{3}\right.$ carbon) and $\mathrm{G}$ band contributes to graphitic structure ( $\mathrm{SP}^{2}$ carbon in Graphite sheet). The ratio of $\mathrm{D}$ and $\mathrm{G}$ band gives the defect ratio. Compared with $\mathrm{GO}$, the defect ratio of AMGO was increased which confirmed the successful amine functionalization on GO [30].

\section{Fabrication of AMGO-CNF Nanopaper}

Nanopapers were prepared using vacuum filtration technique [31]. $20 \mathrm{gm}$ of cellulose ( $3 \mathrm{wt} \%$ ) and $10 \%$ AMGO (w.r.t cellulose wt $\%$ ) were mixed and dispersed using a homogenizer (IKA-25 ULTRA TURRAX). When proper homogeneous dispersion was achieved, the dispersion was casted into nanopaper using vacuum filtration. The fabricated nanopapers were peeled off from the filter and dried on a hot press for 30 min at $60{ }^{\circ} \mathrm{C}$. Figure 3 shows the fabrication of AMGO-CNF nanopaper via vacuum filtration and possible interaction of cellulose and AMGO. The AMGO nanosheets effectively interact with cellulose nanofibers through strong hydrogen bonding interactions as shown inFig. 3 .

\section{FTIR and XRD Studies of CNF and AMGO-CNF Nanopaper}

CNF and AMGO-CNF nanopaper were characterised using ATR-FTIR [32]. Figure 4a shows the FTIR spectra of CNF and AMGO-CNF nanopaper. The peaks of CNF nanopaper show a typical saccharide structure. The peaks at 3335

a

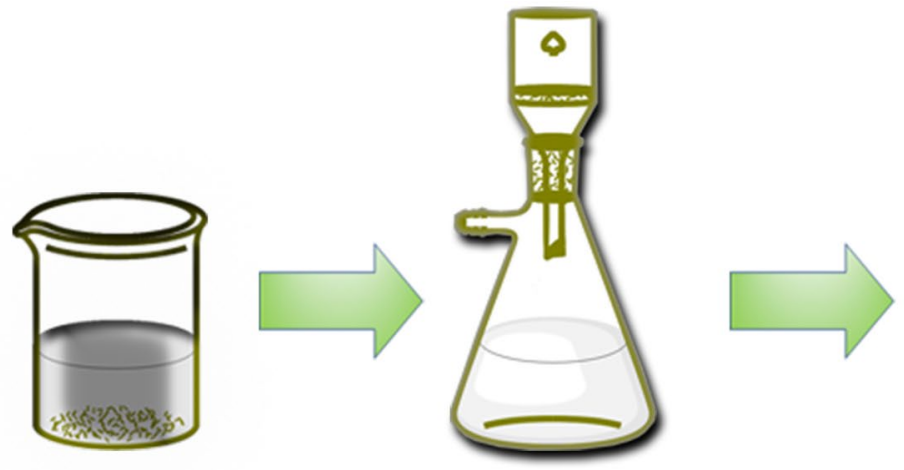

Cellulose-AMGO Dispersion Vacuum Filtration

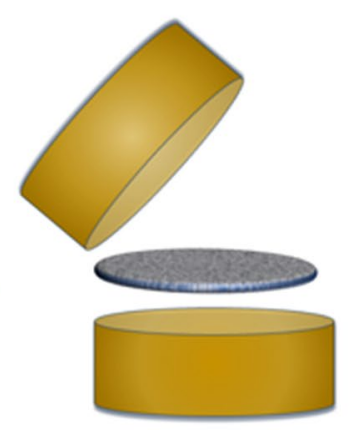

Hot Pressing

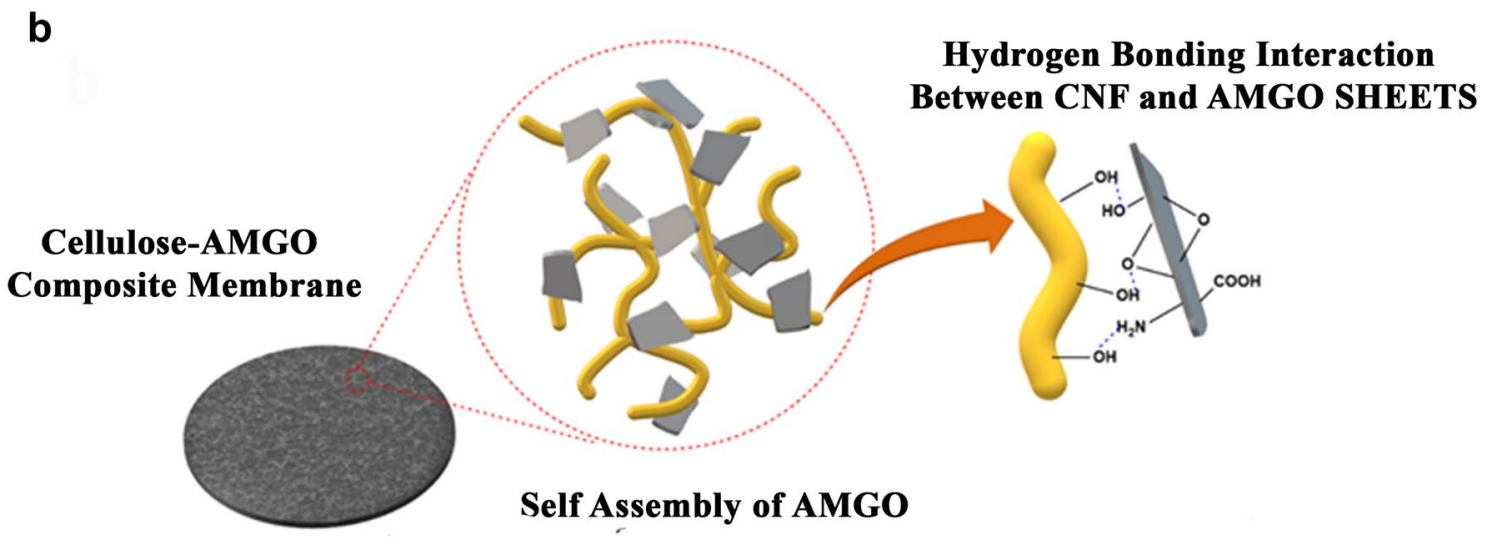

Fig. 3 a Strategy for the Fabrication of AMGO-CNF nanopaper b possible interaction between AMGO and cellulose nanofibers (CNF) 
$\mathrm{cm}^{-1}$ (-OH vibration), $2910 \mathrm{~cm}^{-1}$ (C-H stretching), 1362 $\mathrm{cm}^{-1}$ (- $\mathrm{CH}_{3}$ vibration), $1159 \mathrm{~cm}^{-1}$ (C-O-C anti- symmetric stretching), $1030 \mathrm{~cm}^{-1}$ (C-C-O stretching), $890 \mathrm{~cm}^{-1}$ (C-C stretching), confirmed the cellulosic structure of nanopaper. In the case of AMGO-CNF nanopaper, two distinct sharp peaks at $3330 \mathrm{~cm}^{-1}$ and $3280 \mathrm{~cm}^{-1}$ attributed to $\mathrm{NH}$ stretch, which overlapped with the broad peak arisen from carboxylic acid stretch. Also, compared to CNF the band width at $3330 \mathrm{~cm}^{-1}$ and intensity of all peaks attributed to $\mathrm{OH}$ functional group decreases remarkably which indicates effective reduction of oxygen species during the amination process.

Figure $4 \mathrm{~b}$ shows the XRD spectrum of AMGO, CNF and AMGO-CNF nanopaper. It was clearly evident that, the XRD spectrum of CNF nanopaper showed peaks at $2 \theta=16.3^{\circ}$ and $22.6^{\circ}$ corresponding to (110) and (200) planes. These are typically attributed to cellulose type I structure. AMGO displayed a broad peak at $2 \theta=25.9$ corresponding to the $(002)$ plane of graphitic phase, indicating high extend of reduction [33]. The incorporation of AMGO into CNF matrix affects the crystallinity of CNF. At lower concentration AMGO loading, the AMGO aligned in parallel and facilitated an ordered alignment of CNF molecules leading to an increased crystallinity. These findings were well agreement with Phiri et al. where they showed the enhancement of crystallinity of micro fibrillated cellulose (MFC) upon the incorporation of reduced graphene oxide (RGO) [34]. The enhancement in crystallinity could influence the mechanical properties and porosity.

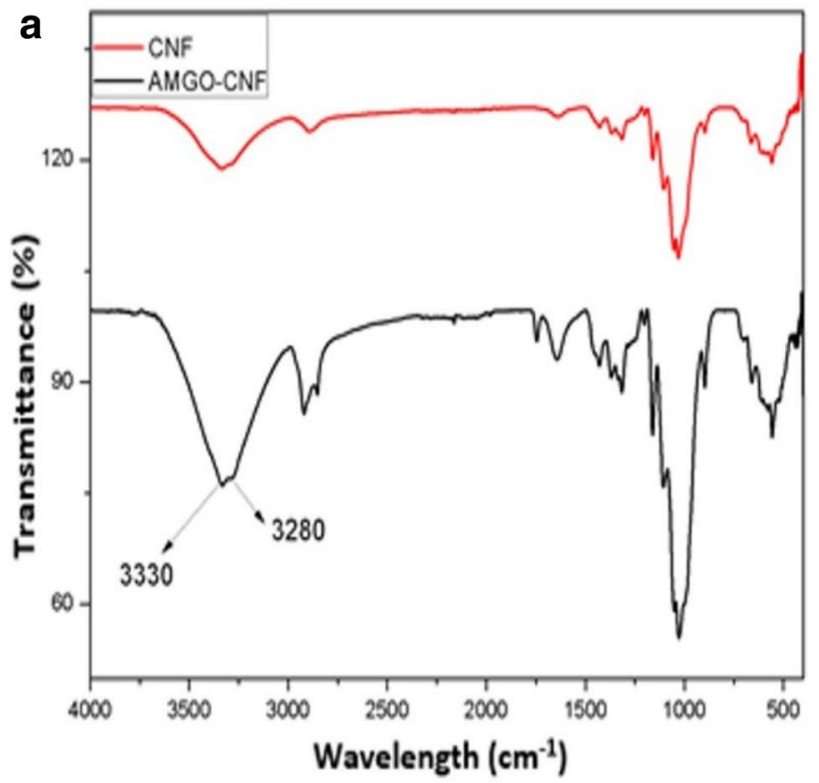

\section{Morphology and Porosity of Fabricated CNF and AMGO-CNF Nanopaper}

Figure 5 shows SEM images of CNF and AMGO-CNF nanopaper [20]. SEM image of CNF displays a nonporous nanofiber arrangement. They are randomly arranged and have empty spaces between fibres. With the addition of AMGO, the empty spaces were filled, and a compact structure could be seen from the SEM image. 3D topological image of CNF and AMGO-CNF nanopaper were shown in Fig. 5b. Surface roughness value mainly depends on three factors, root mean square (Rq), arithmetic mean deviation of roughness $(\mathrm{Ra})$, and height difference between five maximum height peak (Rmax) and five minimum height peaks (Rmin). Usually $\mathrm{Ra}$ is considered to scrutinize the roughness nature. From Table 1 the cellulose nanopaper showed a Ra value of 7.34, without any addition of AMGO. Further, with addition of AMGO, AMGO-CNF nanopaper showed a Ra value of 15.50. The addition of AMGO resulted in the enhanced surface roughness to a greater value. This higher value of Ra might be due to the uniform dispersion of AMGO nanoparticles on the surface

The porosity of CNF and CNF-AMGO nanopaper were determined using gravimetric method using Eq. (1) and the average nanopaper pore radius was calculated by Guerout Elford-Ferry equation given in Eq. (2) in the experimental section [35]. The porosity percentage was found to be $32 \%$ and $51 \%$ for AMG-CNF and CNF nanopaper respectively whereas the average pore radius was found to be $1.9 \mathrm{~nm}$ and $3.2 \mathrm{~nm}$ for AMG-CNF and CNF nanopaper respectively.

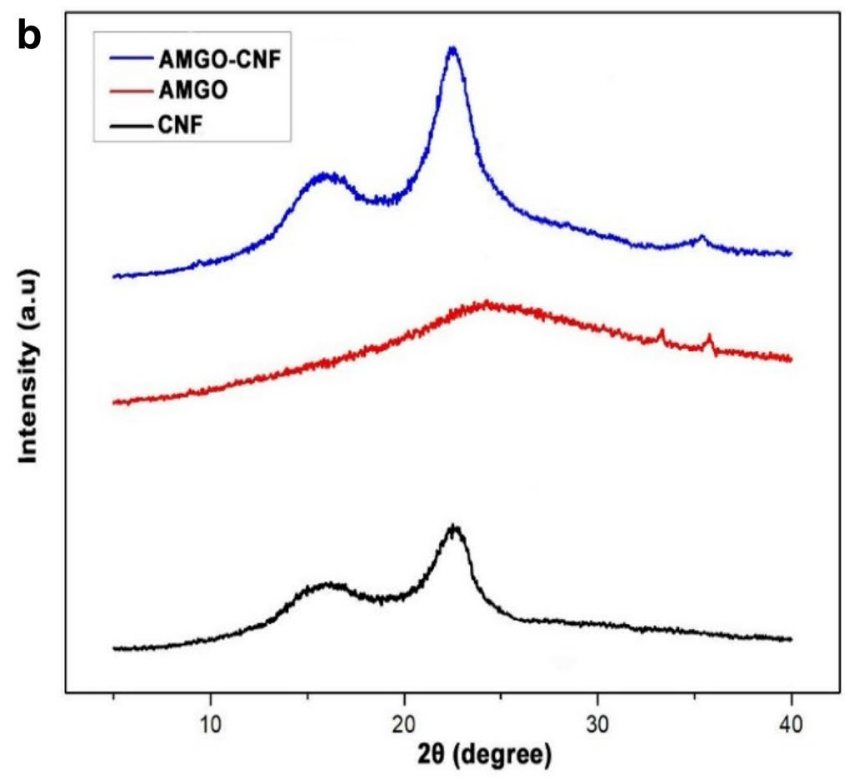

Fig. 4 a FT-IR Spectrum of CNF and AMGO-CNF nanopaper and b XRD spectrum of AMGO, CNF and AMGO-CNF nanopaper 


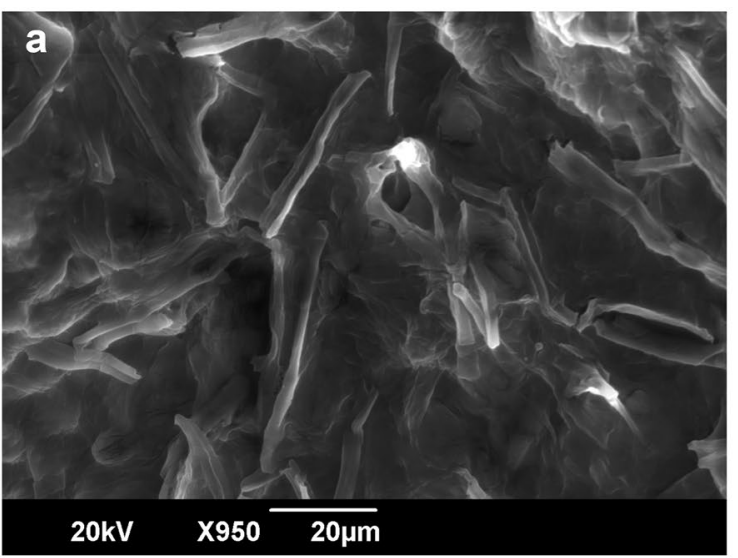

C

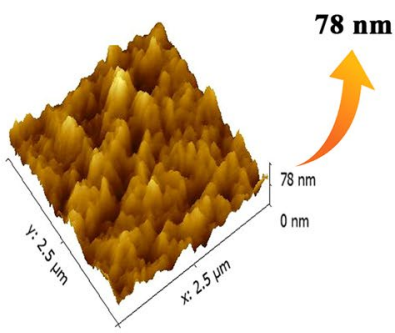

Fig. 5 SEM and AFM images of CNF and AMGO-CNF nanopaper

Table 1 Surface roughness of nanopapers

\begin{tabular}{lcrlr}
\hline Nanopaper & $\mathrm{Ra}$ & $\mathrm{Rq}$ & $\mathrm{Rz}$ & $\mathrm{Rmax}$ \\
\hline CNF & 7.34 & 9.51 & 0.00 & 78.21 \\
AMGO-CNF & 15.5 & 19.70 & 0.00 & 141.40 \\
\hline
\end{tabular}

\section{Evaluation of Adsorption Capacity of AMGO-CNF Nanopaper Against Anionic Methyl Orange Dye}

UV spectroscopy was employed to determine the adsorption capacity of AMGO-CNF nanopaper against anionic dye [36]. Here, we used methyl orange as a model for negatively charged dye. Figure 6 illustrates the adsorption capacity of AMGO-CNF nanopaper as a function of time with different $\mathrm{pH}$ conditions. Result shows that, maximum adsorption was observed at $\mathrm{pH} 2$ with an adsorption value of $7.62 \mathrm{mg} / \mathrm{g}$ at $20 \mathrm{mg} / \mathrm{L}$ concentration. Figure 7 illustrates the proposed removal mechanism of methyl orange (MO) dye by AMGO$\mathrm{CNF}$ nanopaper. Amine groups in AMGO either could be protonated at lower $\mathrm{pH}$ to form $\mathrm{NH}_{3}{ }^{+}\left(\mathrm{R}-\mathrm{NH}_{2}+\mathrm{H}^{+} \rightarrow \mathrm{NH}_{3}{ }^{+}\right)$ or deprotonated at lower $\mathrm{pH}$ to form $\mathrm{NH}_{2} \ldots \mathrm{OH}^{-}$. Zeta potential of different $\mathrm{pH}$ were carried out and found the value of $\mathrm{pH}_{\mathrm{zpc}}$ (Zero Point Charge Fig) of 5.9. $\mathrm{pH}$ below the $\mathrm{pH}_{\mathrm{zpc}}$, AMGO had positive charge and anionic dyes were adsorbed on to the surface of AMGO-CNF nanopaper by electrostatic interaction. The negatively charged anionic dyes were easily

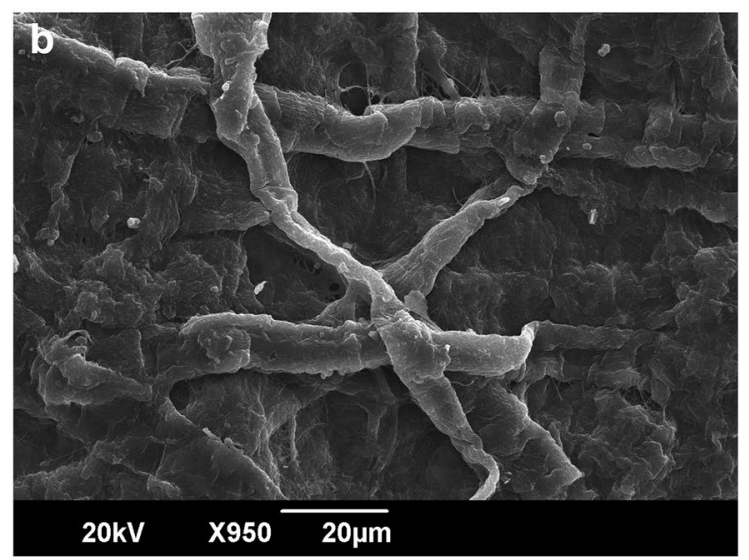

d

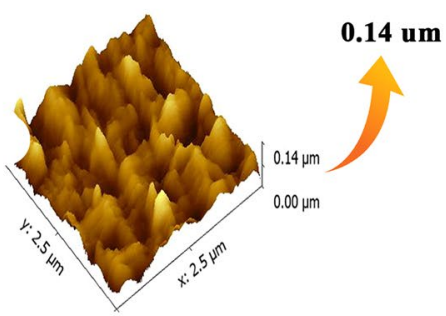

adsorbed by positively charged surface of AMGO in the fabricated nanopaper. At higher $\mathrm{pH}$, the demonstrated AMGOCNF nanopaper showed a decreased adsorption capacity which might be due to the decrease in extend of protonation.

\section{Adsorption Isotherm and Adsorption Kinetics}

Adsorption isotherm describes the equilibrium relationship between adsorbent and adsorb ate [37]. This equilibrium data which describes the interaction of dyes with adsorbent can be expressed via a series of models. Some of the commonly investigating models are Langmuir and Freundlich [38].

Langmuir Equation: $\mathrm{Q}_{\mathrm{e}}=\mathrm{Q}_{0} \mathrm{~K}_{\text {lang }} \mathrm{C}_{\mathrm{e}} /\left(1+\mathrm{K}_{\text {lang }} \mathrm{C}_{\mathrm{e}}\right)$

Linear Form $\mathrm{C}_{\mathrm{e}} / \mathrm{Q}_{\mathrm{e}}=1 / \mathrm{Q}_{0} \mathrm{~K}_{\text {lang }}+\mathrm{C}_{\mathrm{e}} / \mathrm{Q}_{0}$

where $\mathrm{C}_{\mathrm{e}}, \mathrm{Q}_{\mathrm{e}}, \mathrm{Q}_{0}$ and $\mathrm{K}_{\text {lang }}$ are equilibrium concentration of dye solution $(\mathrm{mg} / \mathrm{L})$, amount of dye adsorbed by nanopaper (mg/g), maximum adsorption capacity of nanopaper $(\mathrm{mg} / \mathrm{g}$ ) and Langmuir constant.

Freundlich Equation : $\log \mathrm{Q}_{\mathrm{e}}=\log \mathrm{K}_{\mathrm{f}}+(1 / \mathrm{n}) \log \mathrm{C}_{\mathrm{e}}$

$\mathrm{K}_{\mathrm{f}}$ is the Freundlich constant and $\mathrm{n}$ the heterogeneity factor. $\mathrm{n}$ describes absorbent's adsorption intensity. 

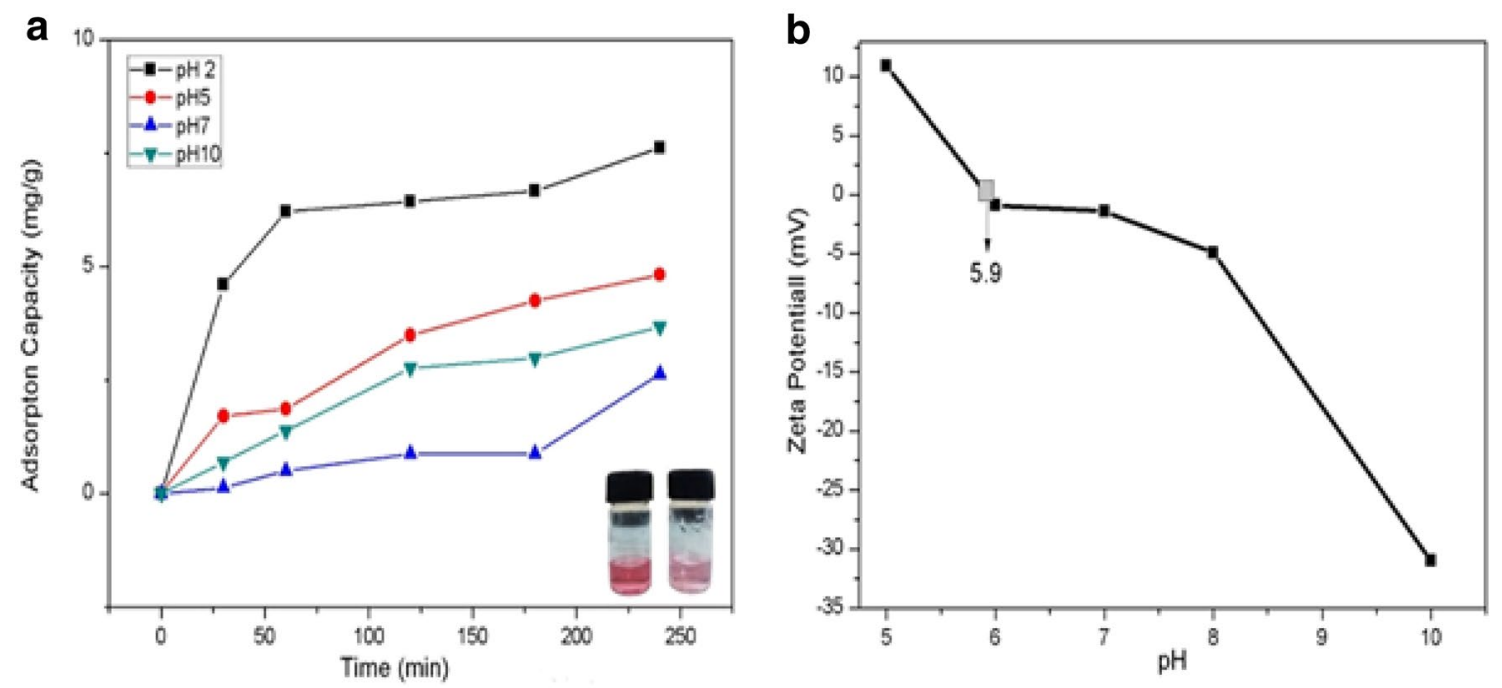

Fig. 6 Adsorption capacity AMGO-CNF nanopaper with a varying $\mathrm{pH}$ and $\mathbf{b}$ zeta potential

Fig. 7 Proposed removal mechanism of MO dye by fabricated AMGO-CNF nanopaper

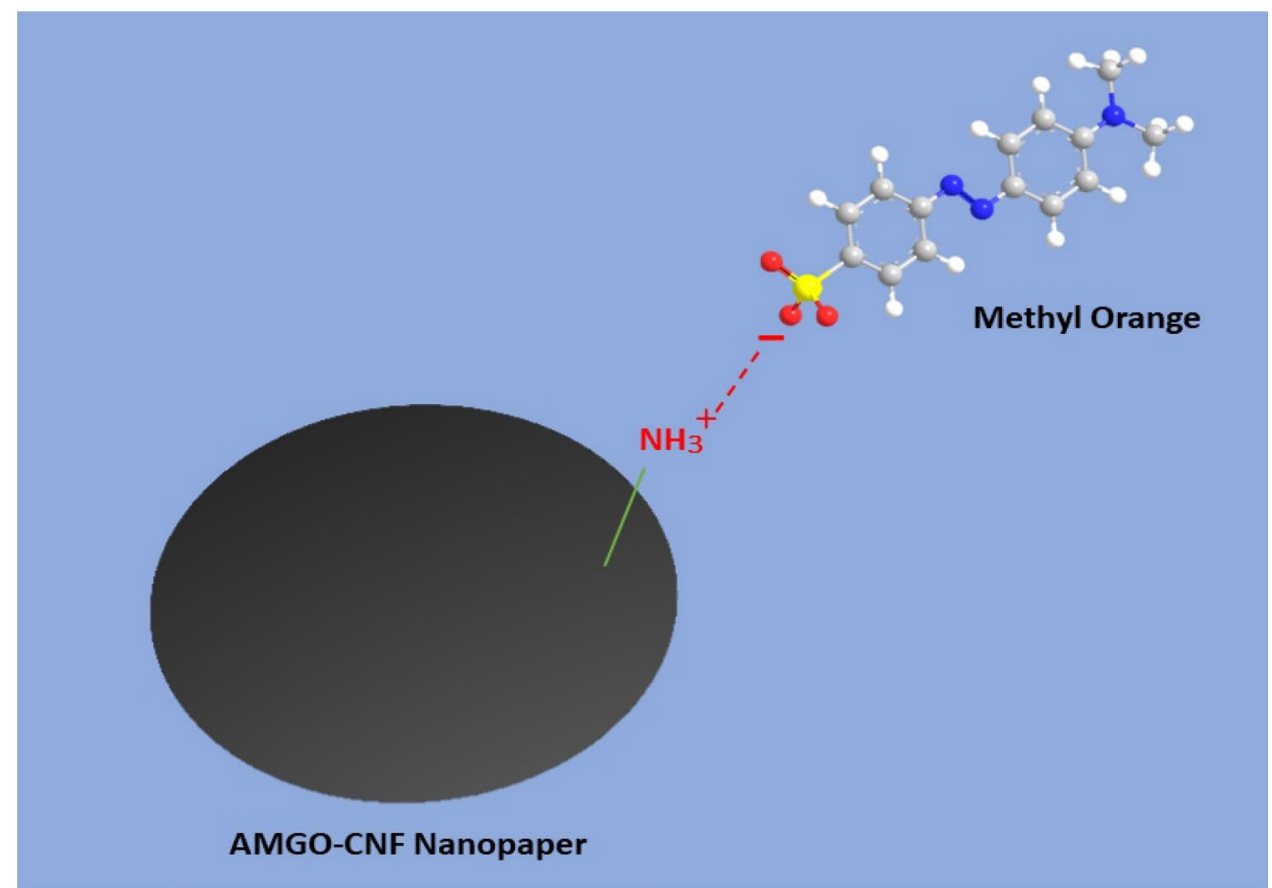

Adsorption isotherm data were plotted using above equations. Other parameters were calculated from linear regression plotting. Langmuir and Freundlich models were plotted out of which Freundlich model apparently fitted better. Figure $8 \mathrm{a}$ shows, the Freundlich model fitting with a correlation coefficient of $\mathrm{R}^{2}=0.919$ and shows that, the adsorption of methyl orange to AMGO-nanopaper via multilayer adsorption. Freundlich theory is based on parameter of nf value. Here we got $1 / \mathrm{nf}$ value of 1.44 which indicates the adsorption was S-type isotherm. This type of isotherm has been observed in low concentration ranges with a polar functional group [39].

Adsorption kinetics explains the rate of chemical reaction and factors affecting the reaction rate [37] Pseudo first order kinetic model and pseudo second order kinetic model were used for kinetic studies.

A linear form of both equations are as follows:

Pseudo First order : $\log (\mathrm{Qe}-\mathrm{Qt})=\log \mathrm{Qe}-\mathrm{K}_{1} \mathrm{t} / 2.303$ 
Pseudo Second order : $t / Q_{t}=2 / K_{e} Q_{e}^{2}+\left(1 / Q_{e}\right) t$

Rate constants and equilibrium adsorption capacity were tested for Pseudo-First order (PFO) and Pseudo-Second order (PSO). Methyl orange adsorption did not follow the pseudo first order (correlation coefficient less). Moreover, pseudo second order showed good correlation for the experiment data (Fig. 7b). Plots of t/qt and t showed good linearity. The PSO rate constant $\mathrm{K}_{2}$, calculated adsorption and the linear regression correlation coefficients value $\mathrm{R}^{2}$ are given in Table 2. The calculated Qe values were in well agreement with experimental adsorption value and correlation coefficient value $\mathrm{R}^{2}$ are higher and close to one.

\section{Antibacterial Action of Nanopapers}

Biofouling due to the action of microbes such as bacteria and viruses is a major challenge for designing materials for water purification. Figure 9 shows the digital image of antibacterial action of AMGO-CNF and CNF nanopapers. The fabricated AMGO-CNF nanopaper showed superior antibacterial activity against E.Coli MTCC 1610 and Klebsiellar. The contact active antibacterial action of the AMGO-CNF nanopaper can be attributed to a combined effect of roughness and surface amino groups of AMGO in AMGO-CNF nanopaper. The characteristic outer membranes of gramnegative bacteria are responsible for their resistance towards antibiotics. The lipopolysaccharides in outer membrane contains phosphate group which would susceptible to interact with amino groups which resulted in the rupture of the bacterial membrane. Table 3 illustrates the zone of inhibition data for different bacteria.

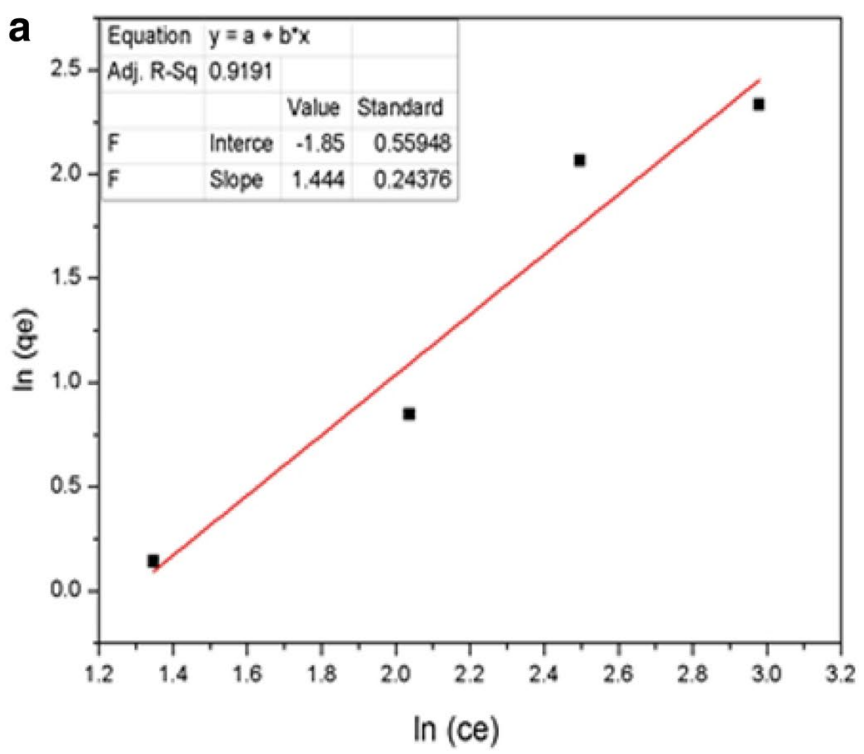

\section{Hydrophilicity of the Fabricated AMGO-CNF Nanopaper}

Figure 10 shows the contact angle of $\mathrm{CNF}$ and AMGO-CNF nanopaper. Contact angle of CNF and AMGO-CNF nanopaper were found to be $43^{\circ}$ and $71^{\circ}$ respectively. The enhancement in contact angle of AMGO-CNF nanopaper was due to the decrease in the hydrophilicity of nanopaper. The $\mathrm{OH}$ groups of CNF could be interacted with amine groups of AMGO in AMGO-CNF nanopaper which resulted in the reduction of $\mathrm{OH}$ groups. This reduction in $\mathrm{OH}$ groups makes the nanopaper less hydrophilic compared with CNF nanopaper. Furthermore, surface roughness also could enhance the contact angle of AMGO-CNF nanopaper which was confirmed from the AFM studies.

\section{Hydrolytic Stability of CNF-AMGO Nanopaper}

Since the fabricated CNF-AMGO nanopaper are intended to use in water purification, it is very relevant to study the hydrolytic stability of these fabricated nanopapers. To investigate the water stability and reusability, the nanopaper were kept in water for $60 \mathrm{~h}$. The pristine CNF nanopaper lost its

Table 2 Kinetic parameter for pseudo second Order

\begin{tabular}{lcll}
\hline Concentration & $\mathrm{qe}, \mathrm{cal}\left(\mathrm{mg} \mathrm{g}^{-1}\right)$ & $\mathrm{K}_{2}\left(\mathrm{~g} \mathrm{mg}^{-1} \mathrm{~min}^{-1}\right)$ & $\mathrm{R}^{2}$ \\
\hline $5 \mathrm{mg}$ & 1.19731 & 0.05169 & 0.98602 \\
$10 \mathrm{mg}$ & 2.3980 & 0.02554 & 0.9838 \\
$20 \mathrm{mg}$ & 7.5318 & 0.01087 & 0.96103 \\
$30 \mathrm{mg}$ & 11.0485 & 0.002879 & 0.9366 \\
\hline
\end{tabular}

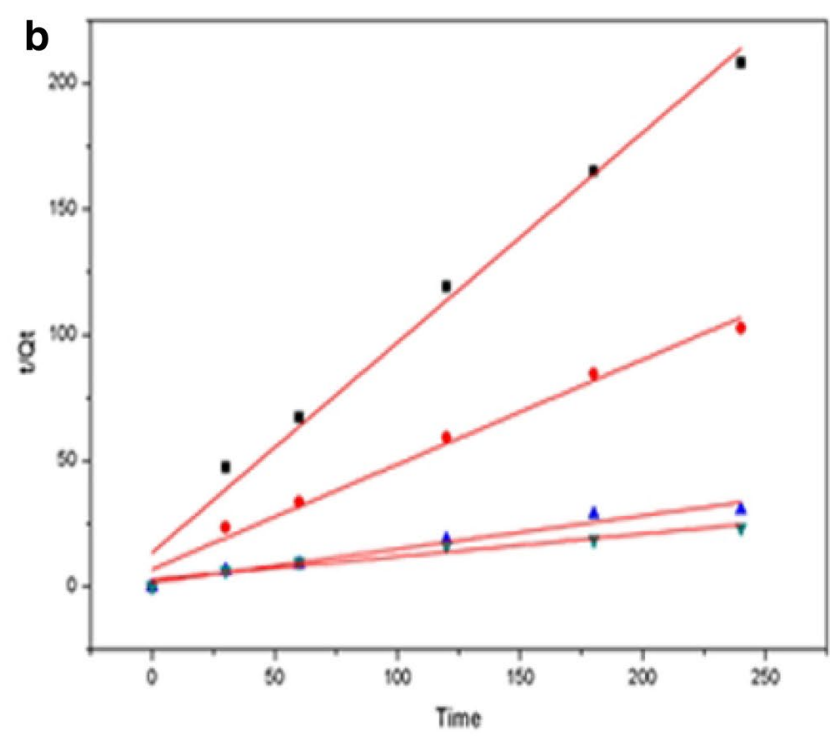

Fig. 8 a Freundlich model plot and $\mathbf{b}$ pseudo second order plot for experiment data 
Fig. 9 Digital image illustrating the antibacterial activity of $\mathrm{CNF}$ and AMGO-CNF nanopaper

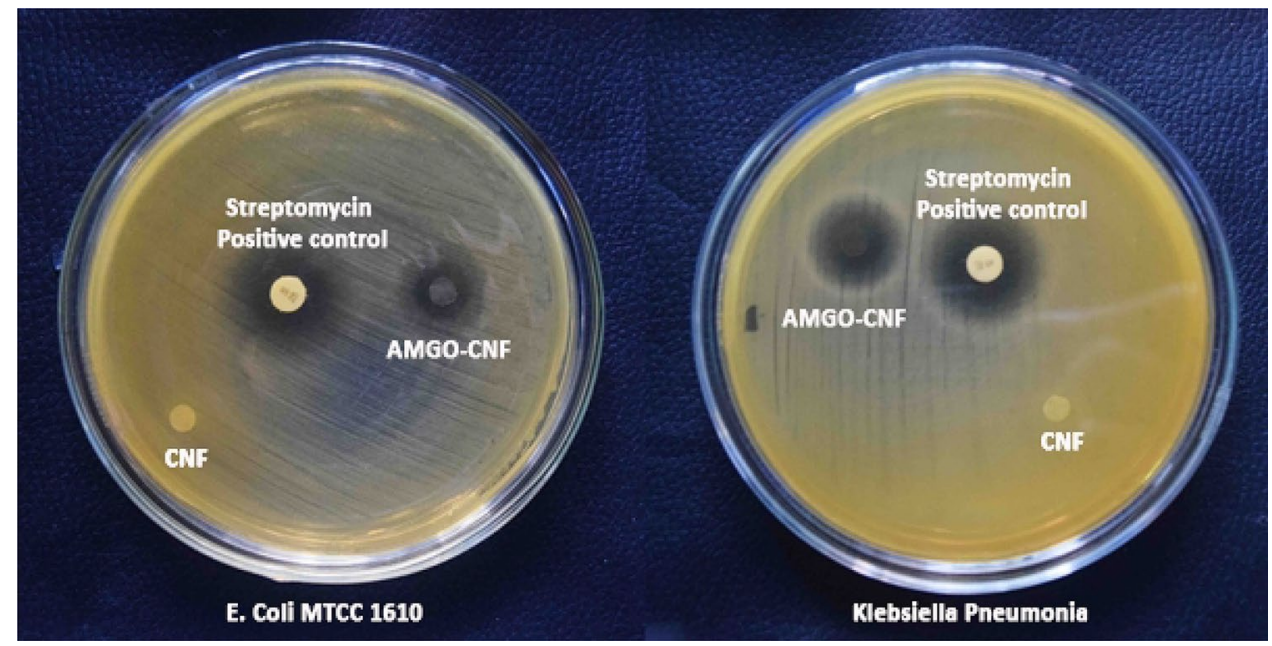

Table 3 Inhibition zone of fabricated AMGO-CNF nanopaper

\begin{tabular}{lll}
\hline Bacterium & Diameter $(\mathrm{mm})$ & $\begin{array}{l}\text { Zone of } \\
\text { inhibition } \\
(\mathrm{mm})\end{array}$ \\
\hline Escherichia Coli & 11 & 14 \\
Klebsiella pneumonia & 11 & 15 \\
\hline
\end{tabular}

stability in water and structurally degraded after $60 \mathrm{~h}$. Figure 11a shows and AMGO-CNF nanopaper before and after soaking in water. There was a weight loss of $28 \%$ in case of CNF nanopaper, whereas in AMGO-CNF nanopaper had a weight loss of $2 \%$. In order to further investigate the hydrolytic stability, both nanopapers were subjected to sonication in water. Figure $11 \mathrm{~b}$ illustrates the hydrolytic stability of both CNF and AMGO-CNF nanopapers after sonication in water for $30 \mathrm{~min}$. The CNF nanopaper started to collapse within $1 \mathrm{~min}$ and completely dispersed in water within 4 min, whereas AMGO-CNF nanopaper had good hydrolytic stability even after the probe sonication for $30 \mathrm{~min}$. The mechanical stability of the nanopaper depends on the structural integrity of the fibre network. The pristine cellulose nanopaper is hydrophilic compared to the fabricated AMGO CNF nanopaper which would undergo rapid swelling and became mechanically poor whereas decreased hydrophilicity in fabricated AMGO-CNF nanopaper reduced the interaction with the water molecules and there by enhanced the wet strength.

\section{Wet Strength of the CNF-AMGO Nanopaper}

Mechanical properties are crucial for nanopaper to work under stress [40]. The nanopapers those works under the pressure driven technology should have sufficient strength for their optimum performance. Table 4 shows the tensile

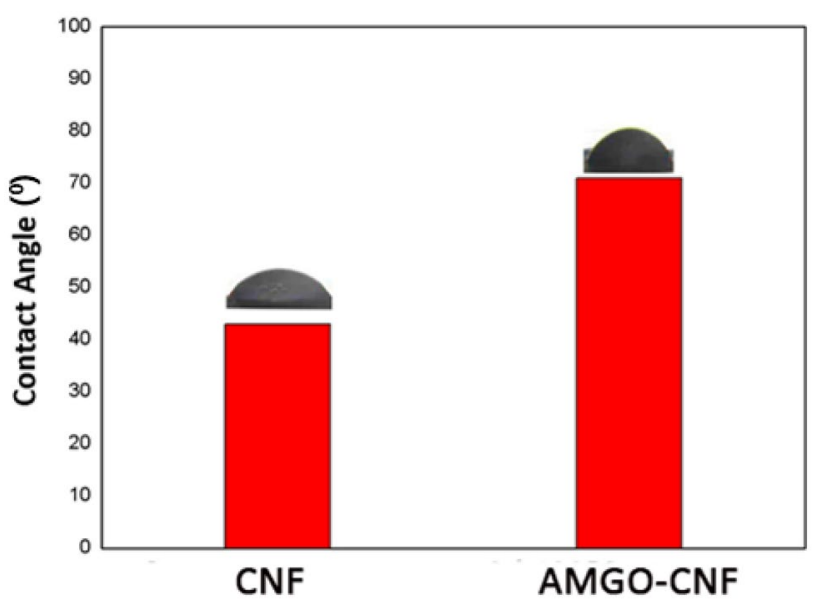

Fig. 10 Contact angle of CNF and AMGO-CNF nanopaper

strength of CNF and AMGO-CNF nanopaper under normal condition and under wet condition. Figure 12 depicts the stress by strain graph of wet CNF and wet AMGO-CNF nanopaper. Pristine CNF nanopaper had a tensile strength of 49.3 Mpa whereas AMGO-CNF nanopapers tensile strength reduces to $38.1 \mathrm{Mpa}$. Both fabricated nanopapers were immersed in water for $30 \mathrm{~min}$ in order to evaluate the wet strength. It was found that, pristine CNF nanopaper had a wet strength of $17.5 \mathrm{MPa}$, whereas AMGO-CNF nanopaper had wet strength of 25.9 MPa. The enhanced wet strength of AMGO-CNF nanopaper was due to the reduction of hydrophilicity after the incorporation of AMGO. The inherent hydrophilic nature of pristine CNF nanopaper resulted in the swelling of the cellulose nanofibers when comes in contact with water. Additionally, CNF nanopaper had $80 \%$ of increase in weight after soaking in water for half hour, whereas AMGO-CNF nanopaper only showed $30 \%$ increase 
Fig. 11 Hydrolytic stability of $\mathrm{CNF}$ and AMGO-CNF nanopaper

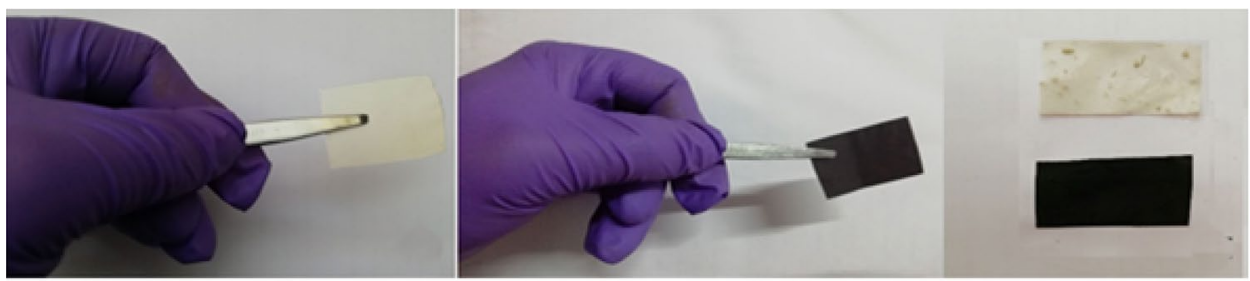

a

After 60hours in water

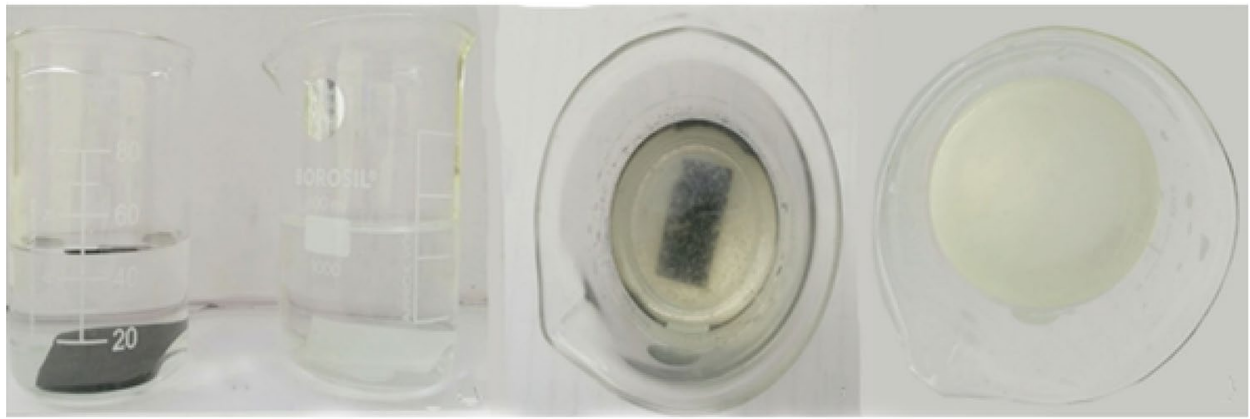

b

After sonication for 30 minutes
Table 4 Mechanical strength of CNF and AMGO-CNF Nanopapers

\begin{tabular}{lll}
\hline Specimen & Dry sample (Mpa) & $\begin{array}{l}\text { Wet } \\
\text { sample } \\
(\mathrm{Mpa})\end{array}$ \\
\hline CNF nanopaper & 38.1 & 17.48 \\
AMGO-CNF nanopaper & 49.3 & 25.9 \\
\hline
\end{tabular}

in weight. Amine functionalised graphene oxide (AMGO) being a strong material could interact with cellulose nanofibers which resulted in the decreased active sites for hydrogen bonding and thereby reduced the swelling behaviour.

\section{Reusability of the AMGO-CNF Nanopaper}

Figure 13 illustrates the reusability of CNF-AMGO nanopaper with $10 \%$ concentration[38]. The reusability of the nanopaper were investigated using $99 \%$ ethanol as desorption agent. These nanopapers were washed and dried at 50 ${ }^{\circ} \mathrm{C}$ for $12 \mathrm{~h}$. It was found that, around $74 \%$ of adsorption retention was achieved after four times of reuse.

\section{Conclusion}

Herein we have fabricated a hybrid cellulosic and amine functionalized graphene oxide nanopaper via a simple vacuum filtration technique. Graphene oxide was prepared using modified hummers method and successfully amine functionalised under a controlled hydrothermal condition.

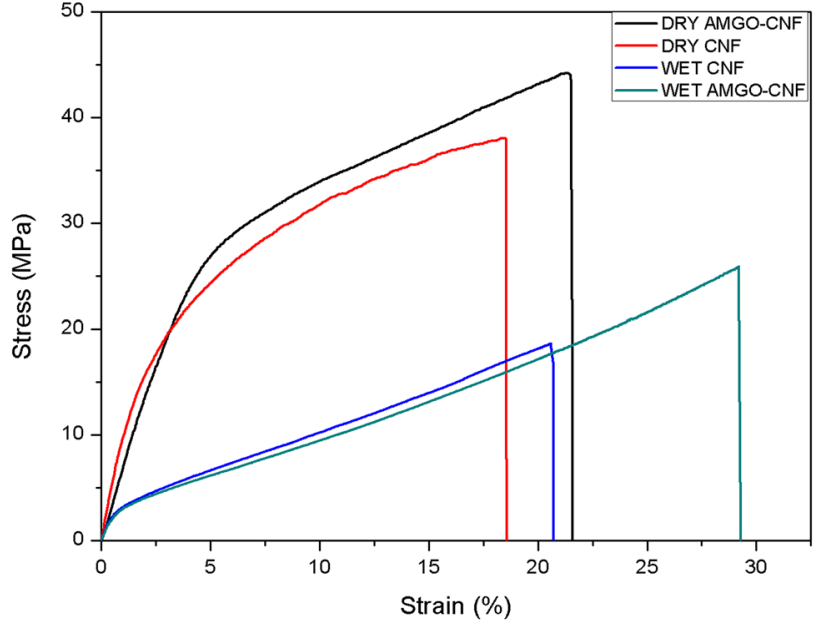

Fig. 12 Stress v/s strain graph of normal and wet nanopapers

This was confirmed by FT-IR and Raman Spectroscopy. The addition of AMGO on to cellulose nanofiber resulted in the enhanced surface roughness which was evident from SEM and AFM images. The increased surface roughness aids the anti-bacterial action of the nanopaper against E.Coli MTCC 1610 and Klebsiella. The demonstrated AMGO-CNF nanopaper exhibited excellent antibacterial action and good anionic dye adsorption without compromising the strength factor. At $30 \mathrm{mg} / \mathrm{l}$ of MO dye, the fabricated AMGO-CNF paper showed an excellent adsorption of $11.05 \mathrm{mg} / \mathrm{g}$ at $\mathrm{pH}$ 2. This adsorption was due to the protonation of amine group. Moreover, it was found that, the protonation decreased with increase in $\mathrm{pH}$. The adsorption data were plotted for adsorption isotherm and 


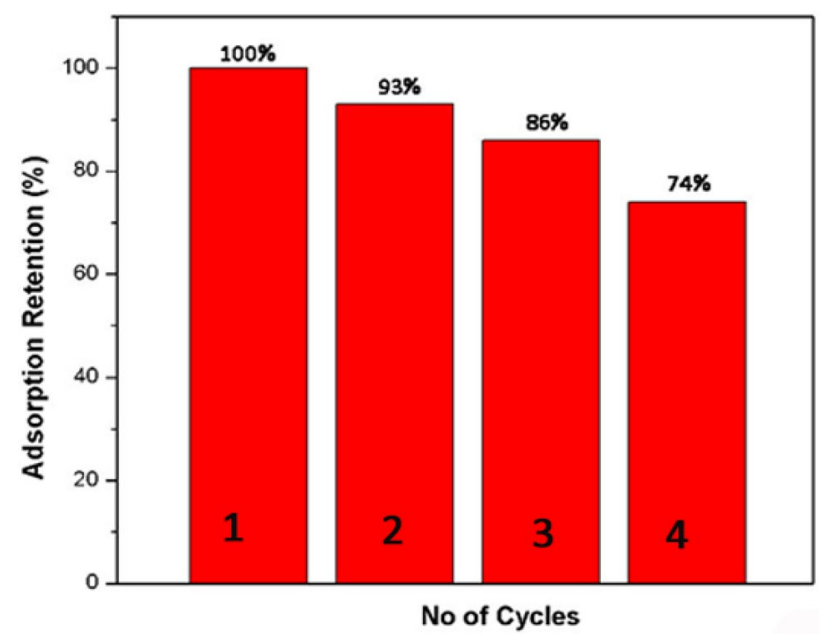

Fig. 13 Reusability of nanopaper after four times of adsorption

its kinetics were investigated. Additionally, the fabricated AMGO-CNF nanopaper exhibited good wet strength of 25.9 with excellent hydrolytic stability even after sonication for $30 \mathrm{~min}$. Moreover, simple fabrication technique with enhanced antibacterial action and adsorption capability using less amount of AMGO opens new platform for the dye adsorption.

\section{References}

1. Pathan TS, Thete PB, Shinde SE, Sonawane DL, Khillare YK (2009) J Bot Res Int 21:71-78

2. Ebenstein A (2012) Rev Econ Stat 94:186-201

3. Haq I, Raj A (2018) Emerging eco-friendly approaches for waste management. Springer, Singapore, pp 121-142

4. Pfaller MA, Flamm RK, Mendes RE, Streit JM, Smart JI, Hamed KA, Duncan LR, Sader HS (2018) Antimicrob Agents Chemother 63:1-12

5. Koksal E, Tulek N, Sonmezer MC, Temocin F, Bulut C, Hatipoglu C, Erdinc FS, Ertem G (2019) Invest Clin Urol 60:46-53

6. Odonkor ST, Ampofo JK (2013) Microbiol Res (Pavia) 4:2

7. Yadollahpour A, Rashidi S, Ghotbeddin Z, Jalilifar M, Rezaee Z (2014) J Pure Appl Microbiol 8:3711-3719

8. Castaing JB, Massé A, Pontié M, Séchet V, Haure J, Jaouen P (2010) Desalination 253:71-77

9. Liang Y, Kim S, Kallem P, Choi H (2019) Chemosphere 221:479-485

10. Andreeßen B, Lange AB, Robenek H, Steinbüchel A (2010) Appl Environ Microbiol 76:622-626

11. Brinchi L, Cotana F, Fortunati E, Kenny JM (2013) Carbohydr Polym 94:154-169

12. Zhao J, Zhang W, Zhang X, Zhang X, Lu C, Deng Y (2013) Carbohydr Polym 97:695-702
13. Valencia L, Arumughan V, Jalvo B, Maria HJ, Thomas S, Mathew AP (2019) ACS Omega 4:4330-4338

14. Zhao Y, Moser C, Lindstrom ME, Henriksson G, Li J (2017) ACS Appl Mater Interfaces 9:13508-13519

15. Espino-Pérez E, Bras J, Ducruet V, Guinault A, Dufresne A, Domenek S (2013) Eur Polym J 49:3144-3154

16. Nechyporchuk O, Belgacem MN, Bras J (2016) Ind Crop Prod 93:2-25

17. Xu X, Zhao G, Wang H, Li X, Feng X, Cheng B, Shi L, Kang W, Zhuang X, Yin Y (2019) J Power Sources 409:123-131

18. Compton OC, Nguyen ST (2010) Small 22:711-723

19. Kim F, Cote LJ, Huang J (2010) Adv Mater 22:1954-1958

20. Zhu C, Liu P, Mathew AP (2017) ACS Appl Mater Interfaces 9(24):21048-21058

21. Fryczkowska B, Wiechniak K (2017) Polish J Chem Technol 19:41-49

22. Meng et al (2017) J Mech Phys Solids 103:22-39

23. Meng et al (2018) Eng Fract Mech 194:350-361

24. Meng, Wang (2019) Appl Mech Rev 71(4):040801

25. Marcano DC, Kosynkin DV, Berlin JM, Sinitskii A, Sun Z, Slesarev A, Alemany LB, Lu W, Tour JM (2010) ACS Nano 4(8):4806-4814

26. Zhao D, Gao X, Wu C, Xie R, Feng S, Chen C (2016) Appl Surf Sci 384:1-9

27. Annadurai G, Juang RS, Lee DJ (2002) J Hazard Mater 92:263-274

28. Elias E, Chandran S, Zachariah AK, Vineesh Kumar VK, Sunil MA, Bose S, Souza FG, Thomas S (2016) RSC Adv 6:85107-85116

29. Shanmugharaj AM, Yoon JH, Yang WJ, Ryu SH (2013) J Colloid Interface Sci 401:148-154

30. Zhang W, Ma J, Gao D, Zhou Y, Li C (2016) Prog Org Coat 94:9-17

31. Gopakumar DA, Pai AR, Pottathara YB, Pasquini D, Carlos L, De Morais M, Luke N, Kalarikkal Y, Grohens, Thomas S (2018) ACS Appl Mater Interfaces 10:20032-20043

32. Garside P, Wyeth P (2006) Stud Conserv 51:205-211

33. Mahdavi H, Kahriz PK, Rajbar HG, Shahalizade T (2017) J Mater Sci Mater Electron 28:4295-4305

34. Phiri J, Johansson LS, Gane P, Maloney TC (2018) Nanoscale 10:9569-9582

35. Guo J, Kim J (2017) RSC Adv 7:33822-33828

36. Gopakumar DA, Pasquini D, Henrique MA, De Morais LC, Grohens Y, Thomas S (2017) ACS Sustain Chem Eng 5:22026-22033

37. Chakraborty S, Chowdhury S, Das Saha P (2011) Carbohydr Polym 86:1533-1541

38. Zhou Y, Zhang M, Hu X, Wang X, Niu J, Ma T (2013) J Chem Eng Data 58:413-421

39. Limousin G, Gaudet JP, Charlet L, Szenknect S, Barthès V, Krimissa M (2007) Appl Geochem 22:249-275

40. Wu YB, Yu SH, Mi FL, Wu CW, Shyu SS, Peng CK, Chao AC (2004) Carbohydr Polym 57:435-440 